\title{
SAM BOWRING - PIONEERING COLLABORATION BETWEEN EARTH SCIENCE AND COMPUTER SCIENCE
}

James F. Bowring ${ }^{1}$, Noah M. McLean ${ }^{2}$, J.D. Walker. ${ }^{2}$

(1) Col of Charleston, Charleston SC 29424, (2) Univ of Kansas, Lawrence, KS 66045

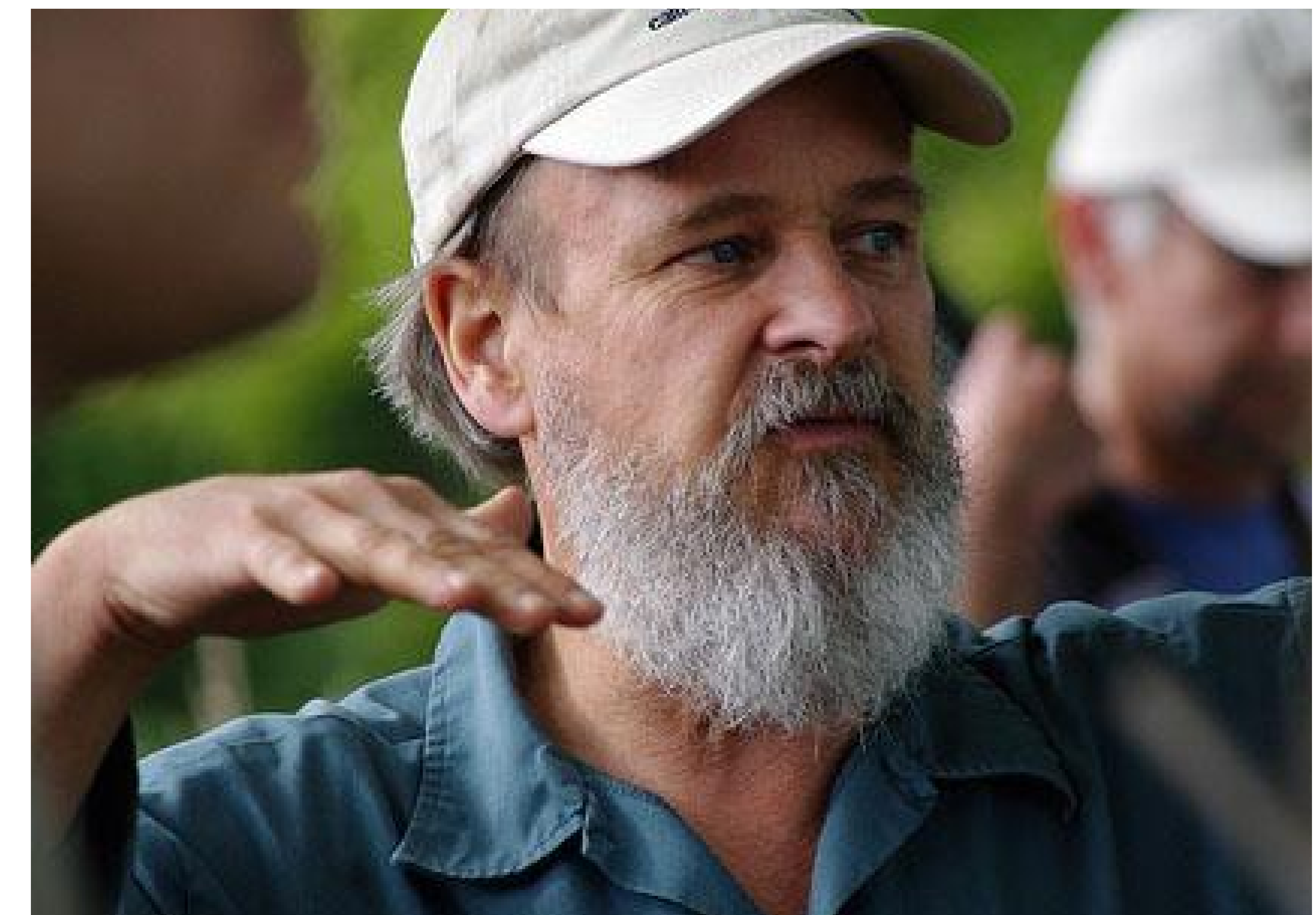

Sam Bowring anticipated and pioneered the development of a first of-its-kind collaboration between geochronologists and computer scientists to develop what he called "cradle to tomb" cyber infrastructure to support the flow of data for geochronology from the field to the laboratory to publicly accessible online databases. He first approached Jim Bowring in 1996 to discuss the problems and to explore solutions, and the work continued to advance from that point. Sam was adamant that earth scientists should not need to engage in computer science to develop tools to support their work, and that there was a great opportunity instead for collaboration with computer scientists to advance science, working together to create software that drives improvements in precision, accuracy, reproducibility, availability, and education. The word "Cyberinfrastructure" would not be coined until 1998, yet Sam Bowring foresaw the need for its key elements and processes.

Over the last twenty years, Sam led the efforts to reify these ideas in concert with the authors and others. He worked with colleagues to establish EARTHTIME in 2001 as a community driven initiative with the goal of calibrating Earth history and developing the geochronological techniques necessary to produce high precision dates.
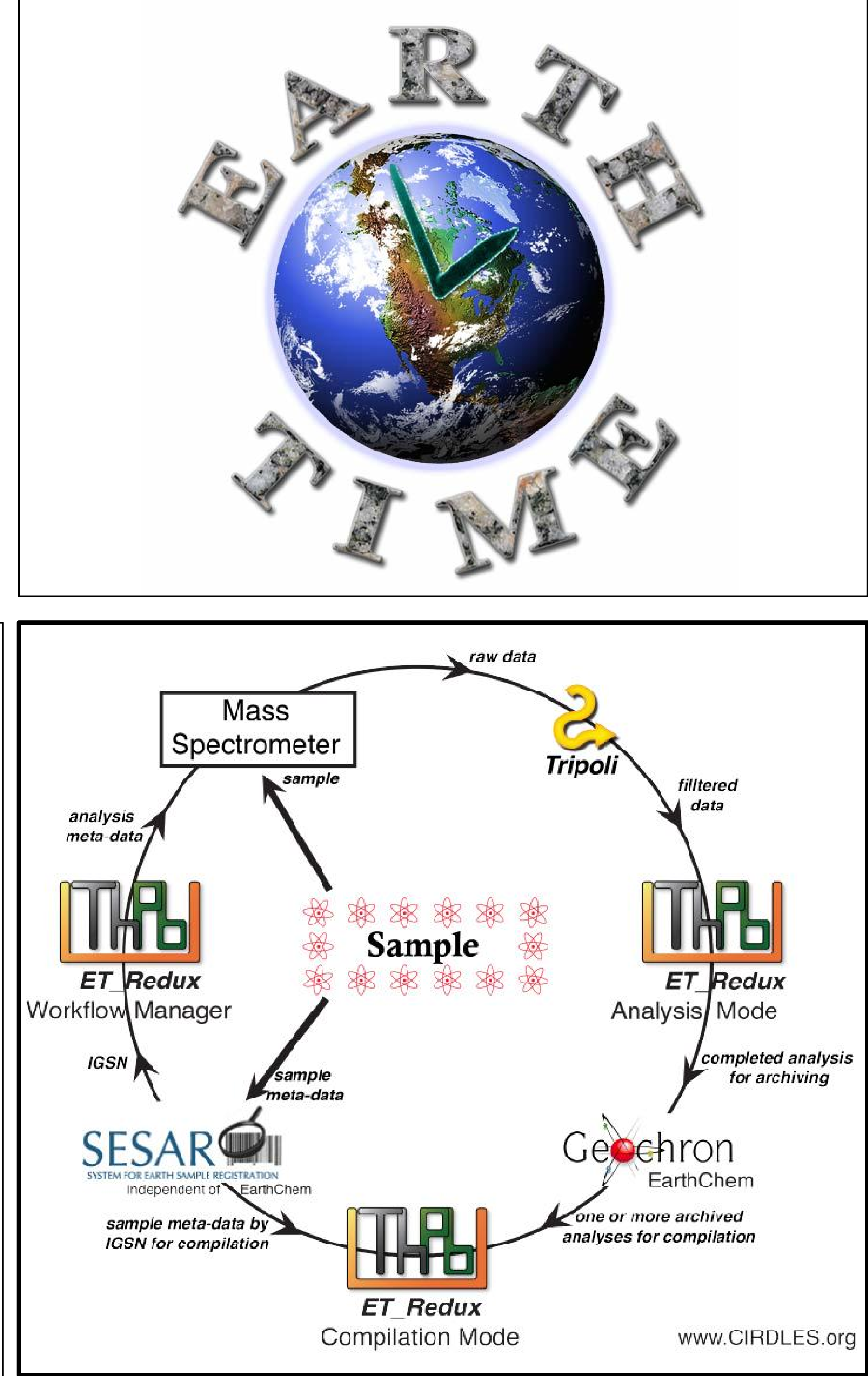

Bowring, J. F., N. M. McLean, and S. A. Bowring (2011), Engineering cyber infrastructure for $\mathrm{U}-\mathrm{Pb}$ geochronology: Tripoli and U-Pb_Redux, Geochem. Geophys. Geosyst., 12, Q0AA19, doi:10.1029/2010GC003479.

McLean, N. M., J. F. Bowring, and S. A. Bowring (2011), An algorithm for $\mathrm{U}-\mathrm{Pb}$ isotope dilution data reduction and uncertainty propagation, Geochem. Geophys. Geosyst., 12, Q0AA18, doi:10.1029/2010GC003478.

McLean, N., J. F. Bowring, and G. Gehrels (2016), Algorithms and software for U-Pb geochronology by LA-ICPMS, Geochem. Geophys. Geosyst., 2016, doi:10.1002/2015GC006097, 15252027.
These techniques include the collaborative development of robust open source software tools to support the scientific workflows of geochronologists including data reduction, analysis, and archiving. The resulting tools Tripoli and ET Redux, developed with the authors and others, now play a key role in $\mathrm{U}-\mathrm{Pb}$ geochronology. One of the most important aspects of his vision and these efforts was his anticipation of open data and the integration of these tools with EarthChem data repositories, especially

Geochron.org, developed with author Doug Walker. Sam and Doug understood the power of open access to data and Sam insisted early on that ET Redux be able to compile archived analyses from data repositories to potentially support novel advances. The overarching theme of Sam Bowring's vision for collaborative development of cyber infrastructure is the potential to improve education at all levels by insisting on transparency and reproducibility.
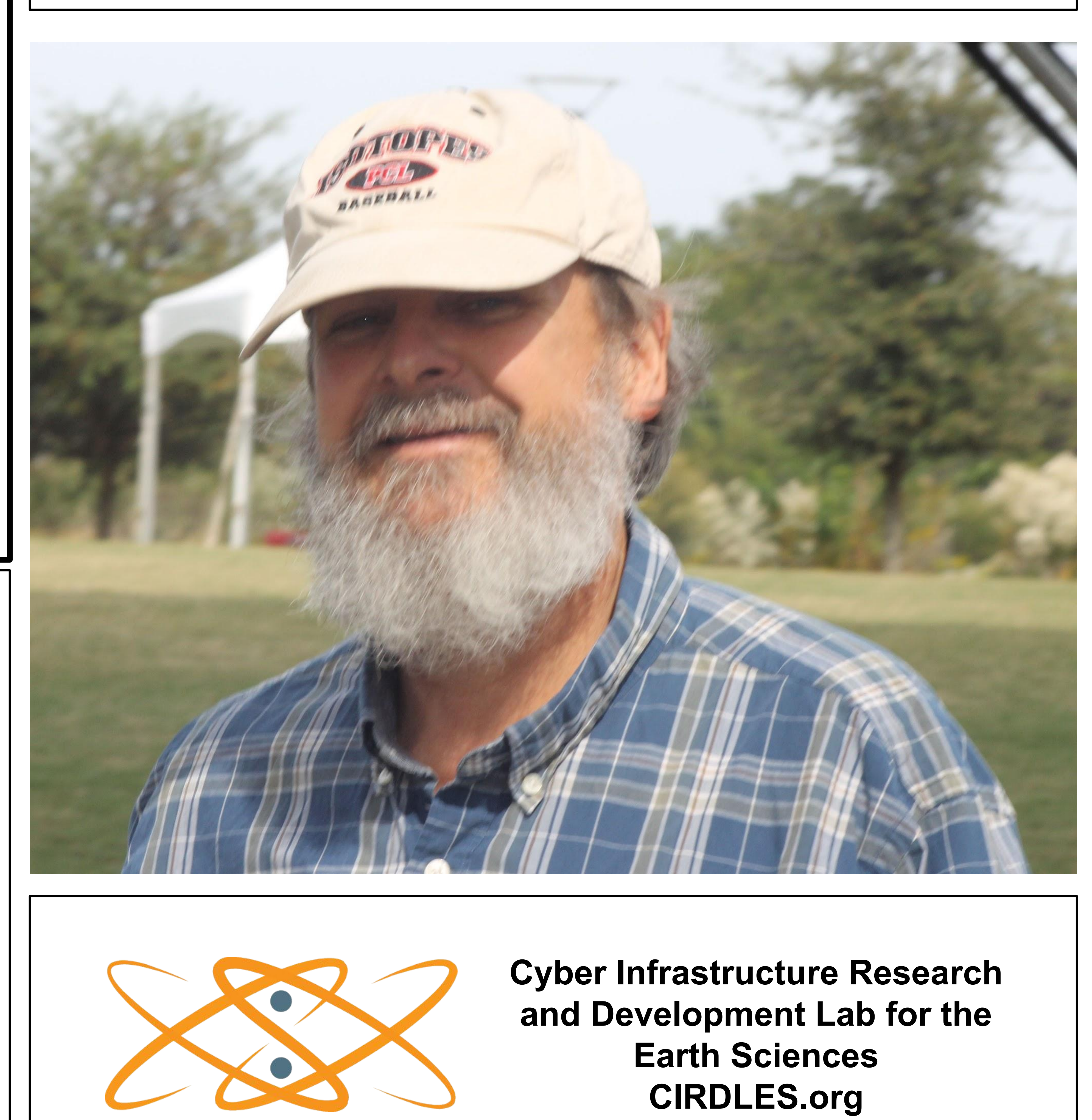

Cyber Infrastructure Research and Development Lab for the Earth Sciences CIRDLES.org 